\title{
Association of diabetes knowledge with glycemic control and self-care practices among Pakistani people with type 2 diabetes mellitus
}

This article was published in the following Dove Press journal: Diabetes, Metabolic Syndrome and Obesity: Targets and Therapy

\author{
Allah Bukhsh ${ }^{1,2}$ \\ Tahir Mehmood Khan ${ }^{1,2}$ \\ Muhammad Sarfraz Nawaz ${ }^{3}$ \\ Hafiz Sajjad Ahmed ${ }^{4}$ \\ Kok Gan Chan ${ }^{5,6}$ \\ Bey-Hing Goh ${ }^{1,2,7,8}$ \\ 'School of Pharmacy, Monash University, \\ Bandar Sunway, Selangor, Malaysia; \\ ${ }^{2}$ Institute of Pharmaceutical Sciences, \\ University of Veterinary and Animal \\ Sciences, Lahore, Pakistan; ${ }^{3}$ Department \\ of Pharmacy, Quaid-i-Azam University \\ Islamabad, Islamabad, Pakistan; ${ }^{4}$ Capital \\ Hospital, Islamabad, Pakistan; \\ ${ }^{5}$ International Genome Centre, Jiangsu \\ University, Zhenjiang, People's Republic \\ of China; ${ }^{6}$ Division of Genetics and \\ Molecular Biology, Faculty of Science, \\ Institute of Biological Sciences, University \\ of Malaya, Kuala Lumpur, Malaysia; \\ ${ }^{7}$ Biofunctional Molecule Exploratory \\ (BMEX) Research Group, School of \\ Pharmacy, Monash University Malaysia, \\ Bandar Sunway, Selangor Darul Ehsan, \\ Malaysia; ${ }^{8}$ Health and Well-being Cluster, \\ Global Asia in the 2 Ist Century Platform, \\ Monash University Malaysia, Bandar \\ Sunway, Malaysia
}

Correspondence: Allah Bukhsh School of Pharmacy, Monash University, Jalan Lagoon Selatan, Bandar Sunway 47500, Selangor, Malaysia

Tel +60 I I 33623703

Fax +6035 5I46364

Email allah.bukhsh@monash.edu

Kok Gan Chan

International Genome Centre, Jiangsu

University, Zhenjiang, People's Republic of China

Tel +60 379677748

Email kokgan@um.edu.my
Objective: This study explored the relationship of disease knowledge with glycemic control and self-care practices in adult Pakistani people diabetes (PWD).

Methods: People diagnosed with type 2 diabetes $(n=218)$ were selected from three health care centers, located in different cities of Pakistan. Disease knowledge and self-care practices were assessed by Urdu versions of Diabetes Knowledge Questionnaire (DKQ) and Diabetes Self-Management Questionnaire (DSMQ), using a cross-sectional design. Chi-square and correlation analysis were applied to explore the relationship of disease knowledge with glycemic control and self-care practices. Linear regression was used to explore the predictors for disease knowledge.

Results: Majority of the sample was $>45-60$ years old (48.8\%), suffering from type 2 diabetes mellitus for $<5$ years $(49.5 \%)$ and had poor glycemic control $(\mathrm{HbA} 1 \mathrm{C} \geq 7 \%$; $\mathrm{n}=181$ participants). Disease knowledge was significantly associated $(p<0.05)$ with patient's gender, level of education, family history of diabetes, nature of euglycemic therapy, and glycemic control. Correlation matrix showed strongly inverse correlations of DKQ with glycated hemoglobin levels $(\mathrm{r}=-0.62 ; p<0.001)$ and strongly positive with DSMQ sum scale $(\mathrm{r}=0.63 ; p<0.001)$. PWD having university-level education $(\beta=0.22$; 95\% Confidence Interval (CI) 0.189, 0.872; $p<0.01$ ), doing job ( $\beta=0.22$; 95\% CI $0.009,0.908]$; $p=0.046)$, and use of oral hypoglycemic agents in combination with insulin $(\beta=-0.16 ; 95 \%$ CI $[-1.224,-0.071] ; p=0.028)$ were the significant predictors for disease knowledge.

Conclusion: Disease knowledge significantly correlated with glycated hemoglobin levels and self-care activities of PWD. These findings will help in designing patient-tailored diabetes educational interventions for yielding a higher probability of achieving target glycemic control.

Keywords: knowledge, glycated hemoglobin, self-management, glycemic control, HbA1c

\section{Introduction}

Type 2 diabetes mellitus (T2DM) is a chronic disease with rapidly increasing prevalence worldwide, but its rate is much higher in low- and middle-income countries such as Pakistan. With an overall prevalence rate of $6.9 \%$, Pakistan has the 10th largest population of people with diabetes (PWD) in the world. ${ }^{1}$ According to recent updates from the International Diabetes Federation (IDF), there are 7.5 million adult cases of diabetes in Pakistan. If appropriate interventional strategies are not adopted, this number is expected to reach 16.7 million by the year $2045 .^{1}$

Effective management of diabetes depends not only appropriate euglycemic medicine use but also on patients' knowledge about their medicines, healthy eating options, 
exercise, and self-monitoring of blood glucose levels. ${ }^{2-4}$ Despite various pharmacological options available today, diabetes prevalence continues to increase. Poor knowledge about the disease and its associated complications among PWD has not only been reported from low- and middle-income countries but from high-income countries as well. ${ }^{5-7}$ Poor disease knowledge is one of the main reasons for inadequate self-care behaviors and glycemic control. ${ }^{8}$ Glycated hemoglobin (HbA1c) is a primary measure for glycemic control in PWD. Poor glycemic control (HbAlc $\geq 7 \%$ ) leads to increased mortality and serious complications such as kidney failure, myocardial infarction, stroke, retinopathy, hypertension, and many other associated micro- and macro-vascular complications. ${ }^{9,10}$

Although disease knowledge alone does not ensure required behavior modifications, the assessment of patients' disease knowledge is a cornerstone is designing tailored health educational intervention. ${ }^{11,12}$ Diabetes education, with consequent improvements in patients' knowledge about disease and self-care activities, results in achieving optimal glycemic control and reduction in disease-related complications. . $^{8,13}$

High prevalence and poor glycemic control among PWD become a challenging health issue of the country. In order to run effective diabetes educational interventions, patients' knowledge about disease must be known. In our recently published study, we have observed that self-care activities of PWD were significantly associated with their glycemic control. ${ }^{14}$ Additionally, we also reported that respondents' level of education and use of oral hypoglycemic agents were significant predictors of their self-care practices. ${ }^{14}$ So far, little is known about the disease knowledge and its association with glycemic control among PWD of Pakistan. Diabetes patients with good knowledge of disease are expected to maintain desired glycemic control. In this study, we attempted to assess the patients' diabetes knowledge and its association with their glycated hemoglobin and self-care activities by using the recently validated Urdu-version of Diabetes Knowledge Questionnaire. ${ }^{15}$ The findings of this study will be helpful in identifying the areas where patients' knowledge about the disease can be improved by designing a patient-tailored diabetes educational intervention in Pakistan.

\section{Methodology}

The cross-sectional study design was adopted using the validated Urdu versions of 24-items Diabetes Knowledge Questionnaire (DKQ) ${ }^{15}$ and 16-items Diabetes SelfManagement Questionnaire (DSMQ) ${ }^{16}$ (English and
Urdu version of DKQ and DSMQ are freely available online, the web addresses for both are provided at the end of the manuscript). Data were collected from PWD between February 2017 to September 2017 in outpatient clinics of three health care facilities located in different cities of Pakistan, namely Capital Hospital Islamabad, Akhuwat Diabetes Clinic Lahore, and Awan Medical Complex Lahore.

\section{Study population}

In order to be included in the study, patients must have been diagnosed with T2DM (for at least 1 year at the time of interview), older than 30 years, had recent glycated hemoglobin (HbAlc) lab test reports (not older than 2 months at the time of interview), able to understand Urdu language, and willing to take part in the study. Patients suffering from other types of diabetes, cognitive impairment, and any terminal illness were excluded from the study.

\section{Sample size}

Daniel's (1999) formula was used for sample size calculation of this study. ${ }^{17}$

$$
\mathrm{n}=\frac{\mathrm{Z}^{2} \mathrm{P}(1-\mathrm{P})}{\mathrm{d}^{2}}
$$

where, $n=$ population sample size, $Z=$ statistic for a level of confidence, $\mathrm{P}$ expected prevalence or proportion, and $\mathrm{d}=$ precision. The minimum required sample size for the study was $n=202$, based on $6.9 \%$ diabetes prevalence in Pakistan, ${ }^{18}$ using $\mathrm{Z}=1.96$ for $95 \%$ level of confidence and precision value $d=0.035$. Thus, data were collected from $\mathrm{n}=230$ subjects, assuming a $10 \%$ attrition rate.

\section{Ethical consideration}

Monash University Human Research and Ethics approved the study (Ethics approval No. 7767) after seeking permission for data collection from the respective health care facilities in Pakistan. Participation in the study was on a voluntary basis. Informed written consent was obtained from each respondent after providing details of study purpose and procedure. In the case of an illiterate person, we took written consent from their accompanying family members. Participants were assured that their identity and information will be kept confidential. 


\section{Data and procedure}

Data were collected from the consenting PWD, who met our study inclusion criteria. Participants' eligibility was determined after reviewing their medical records and with the consultation of the health care professionals at data collection facility ( $\mathrm{n}=760$ ). All adult PWD who fulfilled the eligibility criteria of the study $(n=245)$ were invited to take part in the study. Demographic information of the respondents was collected from the willing participants in a private area of the health care facility. Participants were required to complete two previously validated self-administered questionnaires in the Urdu language. Urdu version of Diabetes Knowledge Questionnaire (DKQ) ${ }^{15}$ was used to measure participants' disease knowledge, whereas, Urdu version of Diabetes Self-management Questionnaire (DSMQ) ${ }^{15}$ was administered to access their self-care practices. For those participants who were illiterate, questionnaires were read out and explained to them, by the investigators. Out of $\mathrm{n}=245$ eligible patients who agreed to participate in our study, 230 PWD finally participated in the study (response rate $93.7 \%$ ). Data were analyzed for $\mathrm{n}=218$ patients, after excluding the incomplete questionnaires.

\section{Study tools}

\section{Patient's socio-demographic and clinical information}

Patients medical record files were used to collect information about their age (years), gender, weight, height, marital status, smoking status, level of education, employment status, family history of diabetes, duration of diabetes, nature of medication, and clinical lab data. Respondents' recent $\mathrm{HbAlc}$ value taken from their medical records was considered as a measure of glycemic control.

\section{Diabetes Knowledge Questionnaire (DKQ)}

The DKQ is a 24-item questionnaire, designed by Starr County Diabetes Education Study, ${ }^{11}$ to elicit information about patients' understanding of the cause of their disease, its associated complications, blood glucose levels, diet, and physical activity. The DKQ has been recently translated and validated for Pakistani PWD in the Urdu language. ${ }^{15}$ The DKQ has three response options "yes", "no", and "don't know". One point is awarded for each correct option, whereas, no point or negative scoring for the incorrect option. Its scoring involves summing-up the points obtained by each participant. A higher score represents better disease knowledge.

\section{Diabetes Self-Management Questionnaire (DSMQ)}

Self-care activities were assessed with 16-item DSMQ. ${ }^{19}$ Translated and validated Urdu-version DSMQ was used in this study. ${ }^{16}$ The DSMQ measures the patient's self-care activity for last the 60 days on a 4-point Likert scale. It has four sub-scales; namely, Glucose Management (GM; comprising 5 items), Dietary Control (DC; comprising 4 items), Physical Activity (PA; comprising 3 items), and 4) Health-Care Use (HU; comprising 3 items). There are seven positively keyed (item no. 1, 2, 3, 4, 6, 8, and 9) and nine reverse-coded items (item no. 5, 7, 10, 11, 12, 13, 14, 15, and 16). The 16th item of DSMQ, which measures overall self-care of the respondent, is only included in the sum-scale. The scoring of DSMQ involves summing-up scores of all items (after reversing nine negatively keyed items) and transforming into a scale ranging from 0 to 10 . A higher score represents better self-care.

\section{Statistical analysis}

Data were analyzed by Statistical Package for Social Science (SPSS 24.0. Inc., Chicago, IL, USA). Demographic and clinical variables were presented by using descriptive statistics. Data distribution was analyzed by the Shapiro-Wilk test. ${ }^{20}$ Mann-Whitney U-test and Kruskal-Wallis test were applied to compare groups with non-normal distribution. American Diabetes Association (ADA) guideline was used to define glycemic control in this study. Patients with values of $\mathrm{HbA} 1 \mathrm{c}<7 \%$ were classified as "good glycemic control", whereas those with $\mathrm{HbA1c} \geq 7 \%$ were classified as "poor glycemic control". ${ }^{21-23}$ Spearman rank-order (two-tailed test) was applied to find the association of DKQ median scores with DSMQ sum scale and its subscales (GM, DC, $\mathrm{PA}$, and HU). Multiple linear regression was applied to identify significant predictors of diabetes knowledge. Statistical tests were considered significant at $p<0.05$.

\section{Results}

The demographic details of the respondents have been presented in Table 1. A total of 230 PWD participated in this study. Whereas, after removing the incomplete questionnaire, data of 218 patients were analyzed. Both genders equally participated in this study (male $=51.4 \%$ and female $=48.6 \%$ ). The majority of the participants, $n=102$, 
Table I Characteristics of the study sample and their association with diabetes knowledge $(\mathrm{N}=2$ /8)

\begin{tabular}{|c|c|c|c|}
\hline Parameter & n (\%); median (IQR) & DKQ sum score median (IQR) & $p$-value \\
\hline Gender & & & $0.04^{\mathrm{a}}$ \\
\hline Male & $112(5 \mathrm{I} .4)$ & $14(11.25-17)$ & \\
\hline Female & $106(48.6)$ & $13(10-16)$ & \\
\hline Age (years) & $52(45-60)$ & & $0.92^{\mathrm{b}}$ \\
\hline $30-45$ years & $65(29.8)$ & $14(1 \mid-16)$ & \\
\hline$>45-60$ years & $102(48.8)$ & $14(10-17)$ & \\
\hline$>60$ years & $51(23.4)$ & $19(11-17)$ & \\
\hline BMI $\left(\mathrm{kg} / \mathrm{m}^{2}\right)$ & $28.53(24.99-32.32)$ & & $0.5 \mathrm{I}^{\mathrm{b}}$ \\
\hline Underweight $(<18.5)$ & $3(1.4)$ & $10(9-10)$ & \\
\hline Normal $(18.5-<25)$ & 51 (22.9) & $13(10-16)$ & \\
\hline Overweight $(25-<30)$ & $85(38.5)$ & $14(\mid 1-17)$ & \\
\hline Obese $(\geq 30)$ & $79(37.2)$ & $13(11-17)$ & \\
\hline Smoking & & & $0.66^{\mathrm{a}}$ \\
\hline No & $205(94.5)$ & $14(10.5-17)$ & \\
\hline Yes & $13(5.5)$ & $13(10-15)$ & \\
\hline Education & & & $0.004^{b}$ \\
\hline No formal education & $48(22)$ & $13(10-15)$ & \\
\hline Primary level & $37(17)$ & $13(9.5-17)$ & \\
\hline Secondary level & $88(40.4)$ & $14(\mid 1-17)$ & \\
\hline University level & $45(20.6)$ & $15(12-19)$ & \\
\hline Family history of diabetes & & & $0.03^{b}$ \\
\hline First degree relatives & $129(59.2)$ & $13(10-17)$ & \\
\hline Second degree relatives & $3(1.4)$ & $10(9-10)$ & \\
\hline Both first and second degree relatives & $17(7.8)$ & $17(13.5-19)$ & \\
\hline No history & $69(31.7)$ & $14(\mid I-16)$ & \\
\hline Working status & & & $0.02^{\mathrm{b}}$ \\
\hline Jobless & $8(3.7)$ & $13(10-15.25)$ & \\
\hline Housewives/stay at home & $104(47.7)$ & $13(10-16)$ & \\
\hline Business & $33(15.2)$ & $13(1 \mid-16)$ & \\
\hline Doing Job & $59(27.1)$ & $15(12-18)$ & \\
\hline Retired & $14(6.4)$ & $15(13-18)$ & \\
\hline Diabetes duration (years) & $5(2-10)$ & & $0.18^{\mathrm{b}}$ \\
\hline$<5$ years & $108(49.5)$ & $14(12-17)$ & \\
\hline $5-9$ years & $44(20.2)$ & $13(10-17.75)$ & \\
\hline$>9-<15$ years & $41(18.8)$ & $13(11-17)$ & \\
\hline$\geq 15$ years & $25(11.5)$ & II (I0-15.5) & \\
\hline Anti-diabetic therapy & & & $0.002^{\mathrm{b}}$ \\
\hline Exclusively insulin & $36(16.5)$ & $13(10-15.75)$ & \\
\hline Combined with medication & $67(30.7)$ & $13(10-15)$ & \\
\hline Oral hypoglycemic agents only & $115(52.8)$ & $15(12-18)$ & \\
\hline HbAlc value (\%) & $8.9(7.27-10.2)$ & & $<0.001^{\mathrm{a}}$ \\
\hline Good glycemic control $(<7 \%)$ & $37(17)$ & $18(16-19)$ & \\
\hline Poor glycemic control ( $\geq 7 \%)$ & I8I (83) & $13(10-15)$ & \\
\hline
\end{tabular}

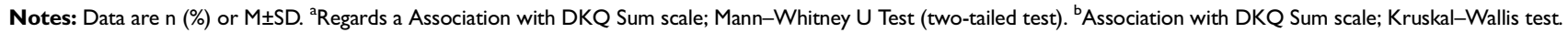
Abbreviations: HbAlc, glycated hemoglobin; BMI, body mass index; DKQ, Diabetes Knowledge Questionnaire. 
were of age ranging from 45 to 60 years, non-smokers (94.5\%), and married (97.7\%). With regard to the level of education, $22 \%$ had no formal education, $17 \%$ had primary level education, whereas, rest $61 \%$ had secondary and university-level education. More than half of the respondents $(59.2 \%)$ reported for a family history of diabetes among their first degree relatives only. Nearly half of the respondents $(49.5 \%)$ were living with diabetes for less than 5 years. Only $22.9 \%$ were having a normal body mass index, whereas $38.5 \%$ were overweight and the rest $37.2 \%$ were obese.

Current pharmacological therapy consisted of oral hypoglycemic agents only in $52.5 \%$; exclusively insulin in $16.5 \%$ and $30.7 \%$ used a combination of oral hypoglycemic agents and insulin. Good glycemic control $(\mathrm{HbA} 1 \mathrm{c}<7 \%)$ was observed in only $17 \%$ of the study participants.

Details of respondents' demographic information and their association with disease knowledge are presented in Table 1.

Diabetes knowledge was significantly related to glycated hemoglobin $(\mathrm{r}=-0.62 . p<0.001)$. PWD having good glycemic control $(\mathrm{HbA} 1 \mathrm{c}<7 \%)$ scored significantly higher $(p<0.001)$ for diabetes knowledge (DKQ sum-scale score 18; IQR 16-19), as compared to those with poor glycemic control (DKQ sum-scale score 13; IQR 10-15).

Patient's age, BMI, smoking status, and duration of diabetes were not found to have statistically significant $(p>0.05)$ association with their disease knowledge. Significantly $(p<0.05)$ higher scores for DKQ sum-scale were obtained by the study respondents with male gender (14; IQR 11.25-17), university-level education (15; IQR $12-19)$, having family history of diabetes in both primary and secondary degree relatives (17; IQR 13.5-19), and those who were using oral hypoglycemic agents only (15; IQR 12-18). (Table 1).

Significantly better $(p<0.05)$ knowledge of disease and blood glucose testing was observed in subjects with good glycemic control; details are presented in Table 2. Strongly positive correlation of DKQ sum-scale was observed with DSMQ sum-scale $(\mathrm{r}=0.63, p<0.001)$, and with three subscales of DSMQ; namely Glucose Management ( $\mathrm{r}=0.61$, $p<0.001)$, Dietary Control ( $\mathrm{r}=0.65, p<0.001)$, and Healthcare Use $(\mathrm{r}=0.55, p<0.001)$. Whereas, a moderately positive correlation was observed between the DKQ sum-scale and Physical activity sub-scale of DSMQ ( $\mathrm{r}=0.44$, $p<0.001)$. Details are presented in Table 3 .
Multiple linear regression analysis was run to predict the patients' disease knowledge (DKQ sum-scale score) based on the patients' gender, age, working status, family history of diabetes, duration of diabetes, level of education, and nature of euglycemic medicine. Significant regression equation was observed $(F(7,210)=4.591$, $p<0.001$ ), with $\mathrm{R}^{2}$ of 0.133 . Respondents' predicted disease knowledge is equal to $12.226-1.037$ (gender) +0.458 (working status) +0.230 (family history of diabetes) +0.530 (level of education) +0.005 (age) -0.019 (duration of diabetes) -0.648 (nature of euglycemic medicine). Regression analysis revealed that respondents' working status ( $\beta=0.21 ;[95 \%$ CI $0.008,0.918] ; p=0.04)$, level of education ( $\beta=0.18$; $[95 \%$ CI $0.108,0.121] ; p=0.01)$ and nature of euglycemic therapy $(\beta=-0.15$; $[95 \% \mathrm{CI}-1.206$, $-0.013] ; p=0.04$ ), were the significant predictors for their disease knowledge. Whereas, patient's gender, duration of diabetes, age, and family history of diabetes were insignificant predictors for patients' disease knowledge. (Table 4)

\section{Discussion}

Health education for patients suffering from chronic diseases is an important source to improve their self-care practices. Existing literature about patients' disease knowledge plays a vital role in designing a patient-tailored and outcome-oriented educational intervention. Diabetesrelated self-care practices, such as, healthy eating practices, being physically activity, blood glucose monitoring, and adhering to the recommended euglycemic therapy, can benefit patients in achieving desired glycemic control. ${ }^{24,25}$ Limited literature is available on disease knowledge of people with diabetes in Pakistan. This study is first of its kind to appraise the association of disease knowledge with glycemic control and self-care practices of PWD in Pakistan.

Our study revealed that disease knowledge was higher among those with university-level education, male gender, doing job, or retired from a job, and the differences were statistically significant $(p<0.05)$. Furthermore, those respondents who had diabetes in their first- and second-degree relatives had better knowledge. Surprisingly, disease knowledge of respondents who were using only oral euglycemic agents was significantly better $(p<0.05)$ than those who were using either insulin alone or in combination with oral euglycemic agents. Improved self-care practices were also observed in our recent study among PWD using oral hypoglycemic agents only. ${ }^{14}$ However, statistically insignificant 


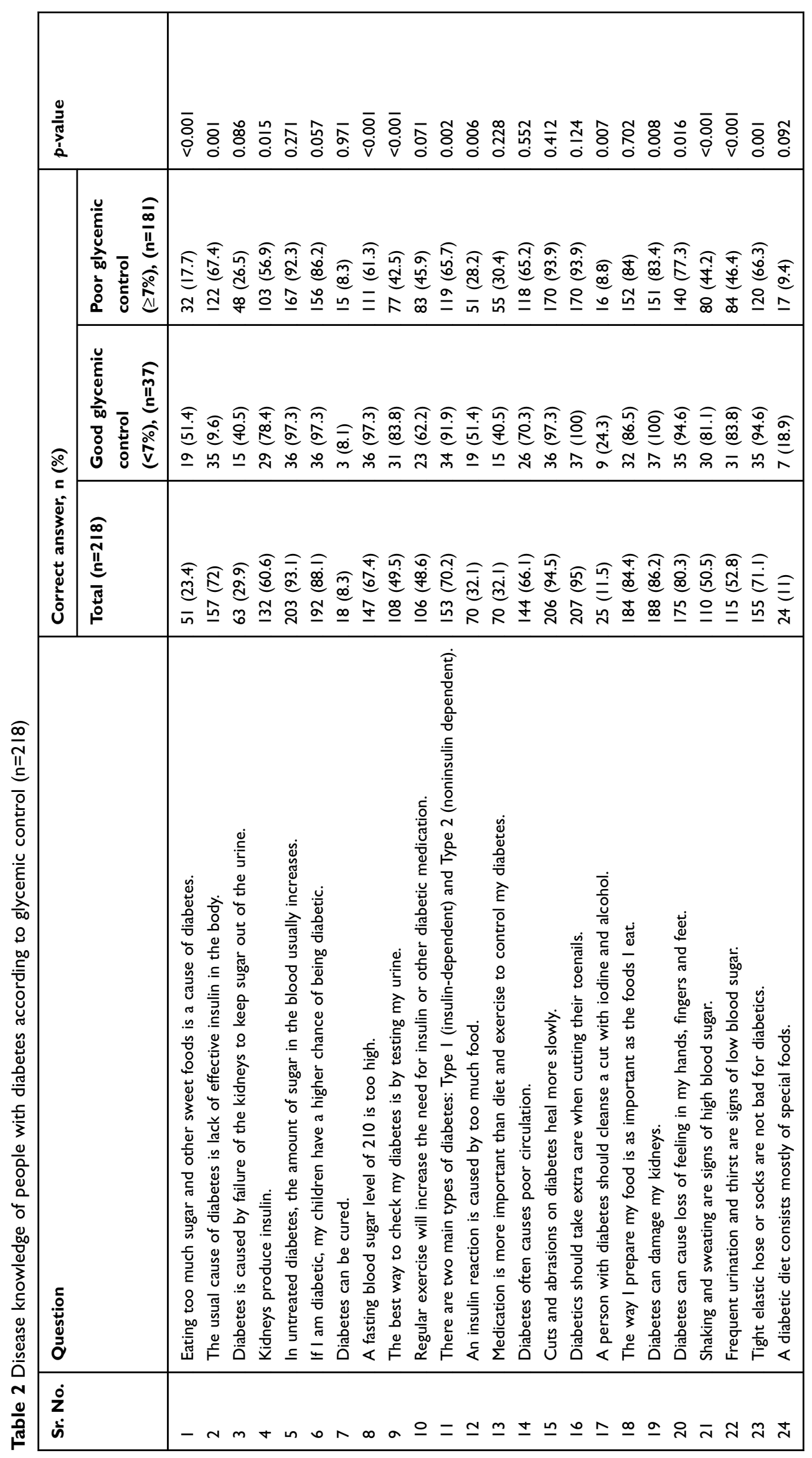


Table 3 Correlation between diabetes knowledge and self-management practices of type 2 diabetes patients $(\mathrm{N}=218)$

\begin{tabular}{|l|l|l|l|}
\hline Parameter & Median (IQR) & Correlation & p-value \\
\hline DSMQ "Sum Scale" & $3.96(2.7 I-6.88)$ & 0.63 & $<0.001$ \\
Subscale "Glucose Management" & $4.67(3.33-7.33)$ & $0.6 \mathrm{I}$ & $<0.00 \mathrm{I}$ \\
Subscale "Dietary Control" & $4.17(2.5-6.88)$ & 0.65 & $<0.00 \mathrm{I}$ \\
Subscale "Physical Activity" & $3.33(1.1 \mathrm{I}-6.67)$ & 0.44 & $<0.00 \mathrm{I}$ \\
Subscale "Health-Care Use" & $4.44(2.22-6.67)$ & 0.55 & $<0.00 \mathrm{I}$ \\
\hline
\end{tabular}

Note: Spearman rank-order (two-tailed test) was applied to check correlation between DKQ and DSMQ scales. The DSMQ scale scores are transformed to a scale ranging from 0 to 10. Abbreviations: DSMQ, Diabetes Self-Management Questionnaire; DKQ, Diabetes Knowledge Questionnaire; IQR, interquartile range.

association $(p>0.05)$ was observed between respondents' age, disease knowledge, and duration of disease.

Good glycemic control was observed in only $17 \%$ $(n=37)$ of the study participants. Like this study, a similar trend was reported in two other studies conducted in urban areas of Pakistan, where good glycemic control was achieved in less than one-third of the study participants. ${ }^{26,27}$ In our study, we found a statistically significant association of $(p<0.01)$ higher diabetes knowledge with low HbA1c levels and better self-care practices. A similar trend was also reported in a study conducted in Ethiopia, where a high level of disease knowledge was significantly associated with patients' literacy and their good self-care practices. ${ }^{8}$ In contrast, Dussa et al reported that disease knowledge in Indian PWD was not correlated with their HbA1c levels. ${ }^{28}$ Besides poor disease knowledge and inadequate self-care practices, poor glycemic control may be partly reflective of more severe disease and treatment not being suitably intensified. Diabetes is a progressive disease and most of the patients in our study (52.8\%) were using OHA and were suffering from diabetes for a longer duration.

Further findings indicated that subjects with good glycemic control scored higher $(p<0.050)$ for knowledge about the disease, its associated complications, normal

Table 4 Linear association of patients demographic characteristics on DKQ, Diabetes KnowledgeQuestionnaire; ( $N=218)$

\begin{tabular}{|l|l|l|}
\hline Predictors & $\boldsymbol{\beta}[\mathbf{9 5 \%} \mathbf{C I}]$ & $\boldsymbol{p}$-value \\
\hline Gender & $-0.14[-2.601,0.527]$ & 0.193 \\
Working status & $0.22[0.009,0.908]$ & 0.046 \\
Anti-diabetes medication & $-0.16[-1.224,-0.07 I]$ & 0.028 \\
Family history of diabetes & $0.09[-0.107,0.567]$ & 0.180 \\
Level of education & $0.22[0.189,0.872]$ & 0.003 \\
Duration of diabetes (years) & $-0.03[-0.103,0.065]$ & 0.651 \\
Age (years) & $0.02[-0.032,0.043]$ & 0.783 \\
\hline
\end{tabular}

Notes: Gender: reference category = female; working status: reference category = jobless; anti-diabetes medication: reference category = oral hypoglycemic agents; education: reference category $=$ no formal education . blood glucose levels, and its monitoring. However, as a whole, majority of the study participants had poor knowledge about diet and physical activity, which was also represented in the form of lower score for DSMQ's subscale "Physical activity" [3.33 (95\% CI 1.11-6.67)] and DSMQ's sub-scale "Dietary control" [4.17 (95\% CI 2.56.88)]. Similar findings were also reported from an urban city of Pakistan (Peshawar), where $75 \%$ of the participants were not performing any form of exercise to control their blood sugar levels. $^{29}$

Besides being physically active, healthy eating practices also play a vital role in diabetes self-care. Inadequate knowledge regarding diet and poor dietary practices could be other contributing factors for poor glycemic control among the study participants. Our results are also consistent with those from low- and middle-income countries, as well as high-income countries, which indicated that glycemic control is associated with disease knowledge and self-care practices of PWD. ${ }^{30,31}$

This study identified several patients' demographic characteristics associated with their disease knowledge. The higher level of patients' education followed by the job status of the respondents was strong predictors for better disease knowledge, which is in line with the findings of previous studies conducted in low- and middle-income countries, where diabetes knowledge was related to patients' education levels. ${ }^{8,28}$ Relating to the present study, only one-fifth $(21 \%)$ of the respondents who had university-level education scored maximum for knowledge about diabetes. Patients' level of education was also identified as a significant predictor for their self-care practices in one of our recently published studies. ${ }^{14}$

Besides pharmacological intervention, improving knowledge and awareness among PWD and their family members will lead to better health-related outcomes. The findings of our study recommend that the contents of an educational intervention should be designed keeping in view the educational status of the patients, as majority of 
the patients with low level of education had poor disease knowledge. Second, while imparting diabetes education, job nature of the PWD must be taken into account, because irrespective of the education-level, the disease knowledge of the majority of our respondents (housewives) was comparable to that of illiterate respondents.

\section{Strengths and limitations}

Assessment of diabetes knowledge and self-care activities by using DKQ and DSMQ, which were recently validated for PWD in Pakistan, is one of the strengths of this study. The study is one of its kind to appraise the association of diabetes knowledge with glycemic control and self-care activities in PWD living in urban areas of Pakistan. One of the limitations of the current study is its cross-sectional design and location of the studied population, as most of the participants were belonging an urban area of Pakistan, so the findings may not be representative of all people living in rural areas. Further limitation includes the possibility of self-reporting bias, as patients might be unwilling to reveal deficiencies in the self-care practices and may not be accurate all the time.

\section{Conclusion}

Peer support approaches are endorsed by WHO as both effective and cost-effective in providing ongoing support to people with diabetes especially for low- and middleincome countries, such as Pakistan. Just as represented in our study findings, most of the PWD had low education levels, so providing education to family members/peers in addition to diabetes patients could prove to be more effective. Improved knowledge about diabetes and self-care practices will help patients to optimize their lifestyle and reduce the chances of diabetes-associated complications. Additionally, health education to PWD family members will also support patients in coping with recommended dietary and other lifestyle modifications. Our findings lend support to tailoring diabetes educational programs for PWD in Pakistan. So culturally sensitive and patienttailored educational interventions by health care providers are likely to be more effective at achieving desired clinical outcomes.

\section{Diabetes questionnaire links}

Diabetes Self-management Questionnaire (Urdu Version) is available online at: https://static-content.springer. com/esm/art\%3A10.1186\%2Fs 12955-017-0776-8/ MediaObjects/12955_2017_776_MOESM2_ESM.pdf.
Diabetes Self-management Questionnaire (English version) is available online at: https://static-content.springer.com/esm/art \%3A10.1186\%2Fs12955-017-0776-8/MediaObjects/12955_ 2017_776_MOESM1_ESM.pdf. Diabetes Knowledge Questionnaire (Urdu version) is available online at: https:// www.frontiersin.org/files/Articles/274955/fpubh-05-00139HTML/image_m/fpubh-05-00139-at001.jpg.

\section{Acknowledgments}

$\mathrm{AB}$ gratefully acknowledges Monash University for providing a PhD Merit Scholarship. KGC thanks the University of Malaya for grantd (PG136-2016A and PG135-2016A). GBH thanks Monash Global Asia in the Twenty-First Century (GA21) for research grants (GAHW-19-L01 and GA-HW-19-501) and the External Industry Grant from Biotek Abadi Sdn Bhd (vote no. GBA-81811A).

\section{Disclosure}

The authors report no conflicts of interest in this work.

\section{References}

1. International Diabetes Federation. IDF Diabetes Atlas - 8th Edition; 2017. Available from: www.idf.org/diabetesatlas. Accessed March 13, 2019.

2. Bukhsh A, Khan TM, Lee S, et al. Efficacy of pharmacist based diabetes educational interventions on clinical outcomes of adults with type 2 diabetes mellitus: a network meta-analysis. Front Pharmacol. 2018;9:339. doi:10.3389/fphar.2018.00339

3. Bukhsh A, Tan XY, Chan KG, Lee L-H, Goh B-H, Khan TM. Effectiveness of pharmacist-led educational interventions on self-care activities and glycemic control of type 2 diabetes patients: a systematic review and meta-analysis. Patient Prefer Adherence. 2018;12:2457. doi:10.2147/PPA.S176067

4. Shrivastava SR, Shrivastava PS, Ramasamy J. Role of self-care in management of diabetes mellitus. J Diabetes Metab Disord. 2013;12 (1):14. doi:10.1186/2251-6581-12-14

5. Al-Maskari F, El-Sadig M, Al-Kaabi JM, Afandi B, Nagelkerke N, Yeatts KB. Knowledge, attitude and practices of diabetic patients in the United Arab Emirates. PLoS One. 2013;8(1):e52857. doi:10.1371/journal.pone. 0052857

6. Deepa M, Bhansali A, Anjana R, et al. Knowledge and awareness of diabetes in urban and rural India: the Indian Council of Medical Research India diabetes study (phase I): Indian Council of Medical Research India diabetes 4. Indian J Endocrinol Metab. 2014;18 (3):379. doi:10.4103/2230-8210.131191

7. Islam SMS, Niessen LW, Seissler J, et al. Diabetes knowledge and glycemic control among patients with type 2 diabetes in Bangladesh. Springerplus. 2015;4(1):284. doi:10.1186/s40064-015-1103-7

8. Kassahun T, Gesesew H, Mwanri L, Eshetie T. Diabetes related knowledge, self-care behaviours and adherence to medications among diabetic patients in Southwest Ethiopia: a cross-sectional survey. BMC Endocr Disord. 2016;16(1):28. doi:10.1186/s12902-016-0114-x

9. Gibbons $\mathrm{CH}$, Goebel-Fabbri A. Microvascular complications associated with rapid improvements in glycemic control in diabetes. Curr Diab Rep. 2017;17(7):48. doi:10.1007/s11892-017-0902-3 
10. Association AD. 5. Glycemic targets. Diabetes Care. 2016;39 (Supplement 1):S39-S46. doi:10.2337/dc16-S008

11. Garcia AA, Villagomez ET, Brown SA, Kouzekanani K, Hanis CL. The starr county diabetes education study development of the Spanish-language diabetes knowledge questionnaire. Diabetes Care. 2001;24(1):16-21. doi:10.2337/diacare.24.1.16

12. Schapira MM, Swartz S, Ganschow PS, et al. Tailoring educational and behavioral interventions to level of health literacy: a systematic review. MDM Policy Pract. 2017;2(1):2381468317714474. doi:10.1177/ 2381468317714474

13. Chrvala CA, Sherr D, Lipman RD. Diabetes self-management education for adults with type 2 diabetes mellitus: a systematic review of the effect on glycemic control. Patient Educ Couns. 2016;99(6):926943. doi:10.1016/j.pec.2015.11.003

14. Bukhsh A, Khan TM, Nawaz MS, et al. Association of diabetesrelated self-care activities with glycemic control of patients with type 2 diabetes in Pakistan. Patient Prefer Adherence. 2018;12:2377. doi:10.2147/PPA.S176067

15. Bukhsh A, Lee SWH, Pusparajah P, Khan AH, Khan TM. Psychometric properties of the Urdu version of diabetes knowledge questionnaire. In: Front Publ Health. 2017;5:139.

16. Bukhsh A, Lee SWH, Pusparajah P, Schmitt A, Khan TM. Psychometric properties of the Diabetes Self-Management Questionnaire (DSMQ) in Urdu. Health Qual Life Outcomes. 2017;15(1):200. doi:10.1186/ s12955-017-0776-8

17. Daniel W. Biostatistics: A Foundation for Analysis in the Health Sciences. 7th ed. New York: R Wiley; 1999.

18. International Diabetes Federation. IDF Diabetes Atlas - 7th ed.; 2016. Available from: http://www.diabetesatlas.org/. Accessed Febuary 13, 2016.

19. Schmitt A, Gahr A, Hermanns N, Kulzer B, Huber J, Haak T. The Diabetes Self-Management Questionnaire (DSMQ): development and evaluation of an instrument to assess diabetes self-care activities associated with glycaemic control. Health Qual Life Outcomes. 2013;11(1):1. doi:10.1186/1477-7525-11-83

20. Ghasemi A, Zahediasl S. Normality tests for statistical analysis: a guide for non-statisticians. Int J Endocrinol Metab. 2012;10(2):486489. doi:10.5812/ijem. 3505
21. Ali MK, Bullard KM, Saaddine JB, Cowie CC, Imperatore G, Gregg EW. Achievement of goals in US diabetes care, 1999-2010. N Engl J Med. 2013;368(17):1613-1624. doi:10.1056/NEJMsa1213829

22. García-Pérez L-E, Álvarez M, Dilla T, Gil-Guillén V, Orozco-Beltrán D. Adherence to therapies in patients with type 2 diabetes. Diabetes Ther. 2013;4(2):175-194. doi:10.1007/s13300-013-0034-y

23. Lee SWH, Lee JY, San San Tan C, Wong CP. Strategies to make Ramadan fasting safer in type 2 diabetics: a systematic review and network meta-analysis of randomized controlled trials and observational studies. Medicine. 2016;95:2. doi:10.1097/MD.0000000000004864

24. Heisler M, Smith DM, Hayward RA, Krein SL, Kerr EA. How well do patients' assessments of their diabetes self-management correlate with actual glycemic control and receipt of recommended diabetes services? Diabetes Care. 2003;26(3):738-743. doi:10.2337/diacare.26.3.738

25. Chiu C-J, Wray LA. Peer reviewed: factors predicting glycemic control in middle-aged and older adults with type 2 diabetes. Prev Chronic Dis. 2010;7:1.

26. Ullah Khan A, Zafar Ali Khan M, Nadeem M, Yasmeen BR, Fakhr A. Status of glycemic control in patients of type 2 diabetes mellitus. Pak Armed Forces Med J. 2013;63:2.

27. Hassan MM, Zafar A, Akram S. Glycemic control and clinical outcomes of diabetic pulmonary tuberculosis patients. Pak J Med Health Sci. 2018;12(1):371-+.

28. Parimalakrishnan S, Dussa K, Sahay R. Assessment of diabetes knowledge using diabetes knowledge questionnaire among people with type 2 diabetes mellitus. Asian J Pharm Clin Res. 2015;8 (2):254-256

29. Gul N. Knowledge, attitudes and practices of type 2 diabetic patients. J Ayub Med Coll Abbottabad. 2010;22(3):128-131.

30. D'Souza MS, Karkada SN, Venkatesaperumal R, Natarajan J. Selfcare behaviours and glycemic control among adults with type 2 diabetes. GSTF J Nurs Health Care (JNHC). 2017;2:1.

31. Houle J, Beaulieu MD, Chiasson JL, et al. Glycaemic control and self-management behaviours in Type 2 diabetes: results from a 1-year longitudinal cohort study. Diabetic Med. 2015;32(9):1247-1254. doi:10.1111/dme. 12686

Diabetes, Metabolic Syndrome and Obesity: Targets and Therapy

Dovepress

\section{Publish your work in this journal}

Diabetes, Metabolic Syndrome and Obesity: Targets and Therapy is an international, peer-reviewed open-access journal committed to the rapid publication of the latest laboratory and clinical findings in the fields of diabetes, metabolic syndrome and obesity research. Original research, review, case reports, hypothesis formation, expert opinion and commentaries are all considered for publication. The manuscript management system is completely online and includes a very quick and fair peer-review system, which is all easy to use. Visit http://www.dovepress.com/testimonials.php to read real quotes from published authors. 